\title{
BALANCED CANTILEVER GIRDER BRIDGE OVER THE DANUBE-BLACK SEA CHANNEL
}

\begin{abstract}
Aldo Giordano, PH.D. Professor of Structural Engineering, ITALROM Inginerie Internationala, e-mail: a.giordano@italrominginerie.com

Giorgio Pedrazzi, Chief Structural Engineer, ITALROM Inginerie Internationala, e-mail: g.pedrazzi@italrominginerie.com
\end{abstract}

Giovanni Voiro, Structural Engineer, ITALROM Inginerie Internationala, e-mail: g.voiro@italrominginerie.com

\section{Abstract}

This paper describes the design and construction of a "balanced cantilever girder" bridge over the Danube-Black Sea channel, characterized by a central span of $155 \mathrm{~m}$ with two symmetrical side spans of $77.5 \mathrm{~m}$. The total length of the bridge, including portions of the abutments support, is $312.0 \mathrm{~m}$.

The bridge main features, from calculation as well as construction points of view, are in particular the post-tensioning tendons, distributed both a top and bottom sides of the section along the bridge. The former ones play a key role in the construction phase, for the need of counterbalancing selfweight while subsequent segments are realized.

Tendons are symmetrical about midspan, with anchors positioned at the end of each segment.

Bridge deck is supported by two piers outfitted with friction pendulum seismic bearings, which develop friction both in static conditions to withstand static forces and small displacements, and in dynamic conditions, causing dissipation. Under severe earthquake load all structures (deck and piers) develop only elastic behavior.

This papers presents a detailed review of the design process as well as a time journey during construction

Keywords:, FE non linear analysis, seismic isolation, time-dependent material properties, staged construction, balanced cantilever bridge

\section{INTRODUCTION}

This bridge is "balanced cantilever girder" type and it is characterized by a central $155 \mathrm{~m}$ span, with two side symmetric $77.5 \mathrm{~m}$ spans.

The total length of the bridge, including segments at abutments supports, is $312.0 \mathrm{~m}$. The deck shows varying-depth through the spans, provided by a curved soffit, which characterize the typical parabolic shape of the deck girder. 
ROMANIAN JOURNAL

\section{OF TRANSPORT INFRASTRUCTURE}

The depth of the deck cross section varies from a maximum value of $10.0 \mathrm{~m}$, at the pier axis, to a minimum value of $2.40 \mathrm{~m}$, at the mid span and the abutments supports.

The upper slab is $14.75 \mathrm{~m}$ wide and transversally inclined at $2.5 \%$, same as the road transverse slope. The upper slab shows a variable thickness from a minimum of $25 \mathrm{~cm}$, at the center of the box girder section, to a maximum of $45 \mathrm{~cm}$, at two intermediate web supports.

The box girder section is characterized by a depth of the bottom slab of variable thickness, which is maximum near the pier to keep the compression at the bottom fiber compressions below the maximum allowable at this location. The thickness of the concrete webs is $30 \mathrm{~cm}$ for the center spans segments and $40 \mathrm{~cm}$ segments closest to pier segments .

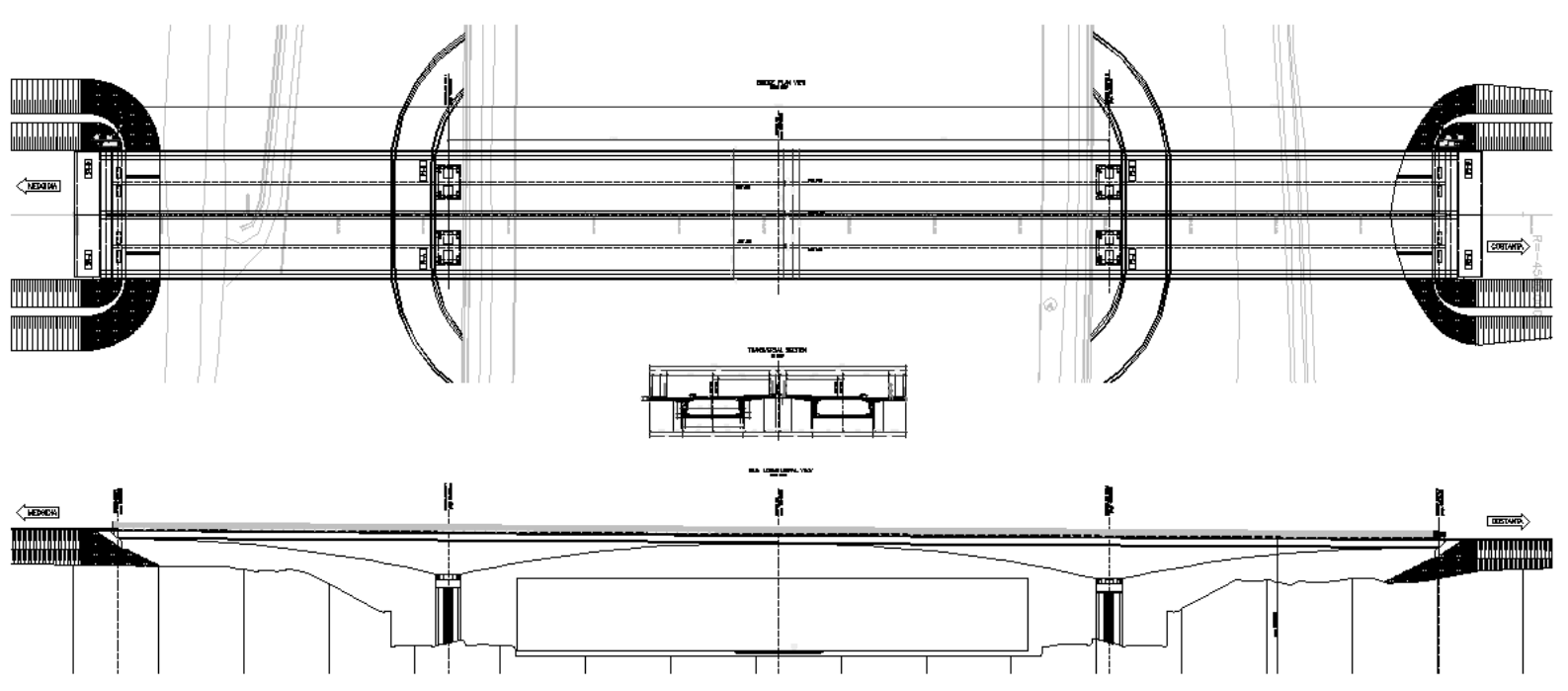

Figure 1. Plan scheme of the bridges

The deck is characterized by internal tendons, positioned in the top and bottom slab. The upper tendons play an important role during construction phases because of their counterbalance action against the activation of segments self-weight, then to reduce the vertical deflection of the free cantilever under gravity loads.

The upper tendons are symmetric to the pier, with a linear path in the upper slab and short vertical deviation near the tendon end anchorages. The tendon anchorages are located at the end of each segment in both web at top position, where it has been defined a wider thickness zone up to $70 \mathrm{~cm}$. The lower tendons, activated at the end of free cantilever construction stage, are located along bottom slab. The tendon end anchorages are located in specific r.c. 
internal blisters. The lower tendon layout is symmetric at mid central span and located at end of side spans. The bridge deck is supported by two piers and two abutments through seismic bearings. At each support there are two bearings type "friction pendulum" which develop friction both in static condition, to asses static forces and small displacements, and dynamic condition, providing dissipation. Under rare seismic load all structures (deck and elevations) develop only elastic behavior, because dissipation provided by seismic bearings. As precaution at piers support a shear key by r.c. is located to prevent deck overtaking.

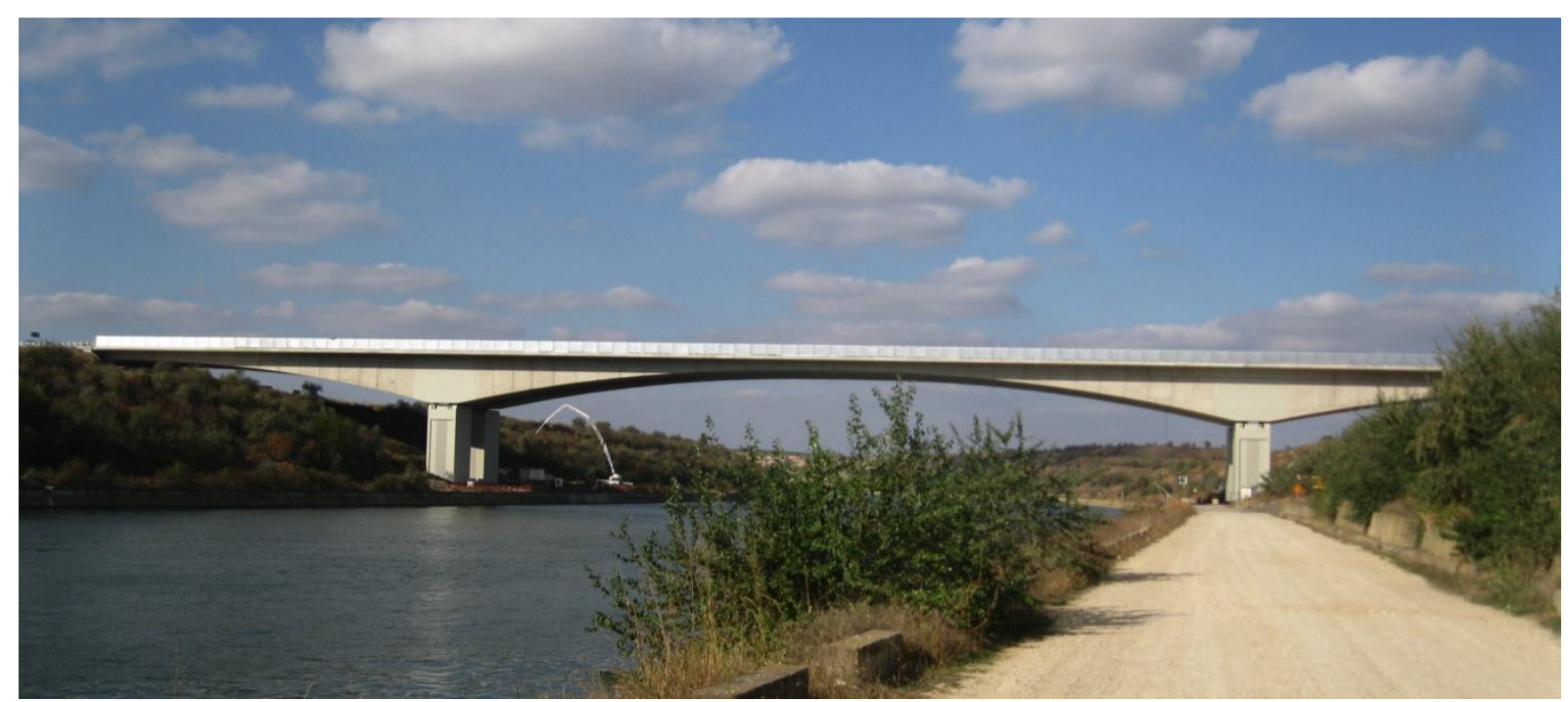

Figure 2. The bridges in their final configuration

Peer 1 and 2 are characterized by same shape but different height, respectively $17.40 \mathrm{~m}$ and $16.15 \mathrm{~m}$. The pier has hollow rectangular section with $8.0 \mathrm{~m}$ transverse and $6.0 \mathrm{~m}$ longitudinal external dimensions and $60-80 \mathrm{~cm}$ web thickness. At the top of the pier there is a pier cap, of same external dimensions of pier current section and $2.0 \mathrm{~m}$ height. At the top of pier cap are located two bearing r.c. block that transfer the vertical and horizontal deck reactions.

Piers base section is connected to an r.c. massive rectangular footing, of $11.0 \mathrm{mx} 13.0 \mathrm{~m}$ dimensions and $2.0 \mathrm{~m}$ thickness, which is founded to a ring of diaphragm walls able to transfer to the ground, the static and seismic forces coming from the superstructure.

Both abutments are spill-through type. The reason of this choice of because of the relevant height of the back embankment, that reach $8.8 \mathrm{~m}$ in SP1 and $10.5 \mathrm{~m}$ in SP2, and the high seismic action that could be developed by a traditional full abutment wall. 
The abutment structure has a top beam seat of L shape that is connected to the back wall. The beam seat collect bridge deck vertical and horizontal reactions, through bearing seismic devices, and earth backfill pressure of the embankment. The beam seat is supported by a number of shear walls of rectangular section, $1.0 \mathrm{~m}$ thickness and $4.3 \mathrm{~m}$ length, aligned with longitudinal deck axis. Each shear wall is founded, trough an intermediate footing r.c. beam $\mathrm{h}=1.5 \mathrm{~m}$, to two deep diaphragm walls that transfer to the ground the static and seismic loading due to superstructure and earth pressures.

The seismic design of the bridge has been assessed through refined analysis. In details it has been assumed that under extreme seismic actions (Ultimate Limit State) the bridge develop dissipation at "friction pendulum" bearings.

\section{ANALYSIS}

The bridge have been analyzed by detailed finite element models to assess the structural behavior of the deck, piers and abutments and the different applied load/boundary condition. The global bridge finite element model is characterized by "beam" elements of different geometry according to the variable shape of the bridge deck and piers.

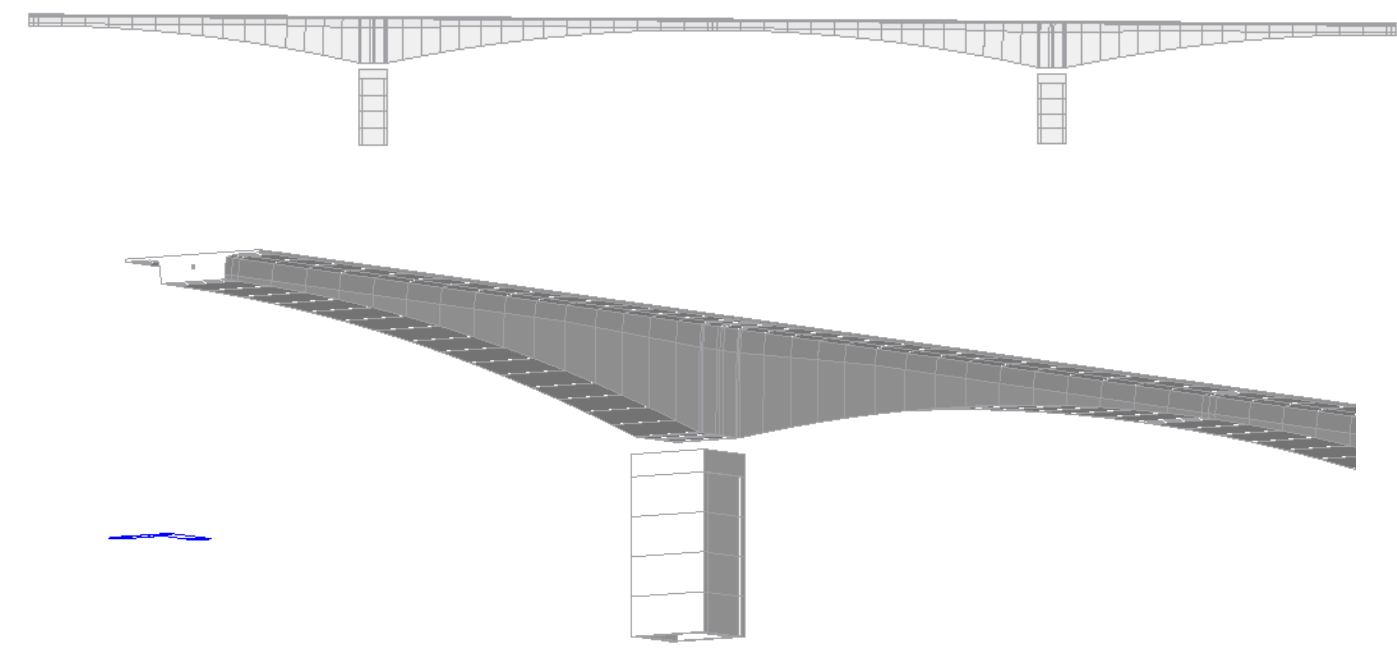

Figure 3. views of the 3D finite element model

Besides the global model of the bridge, different models were created to analyze every part of the bridge structure, which requires a more detailed 
analysis. For this reason, segments and abutments were analyzed separately. The following figures display the model in the different phases.

Global finite element model of the bridge is characterized by "beam" elements with different geometry, suitably variable form of the bridge deck and piers.

Different phases of construction of the bridge were considered to enable / disable loading - bridge segments - limits - prestressing and development timedependent material properties.
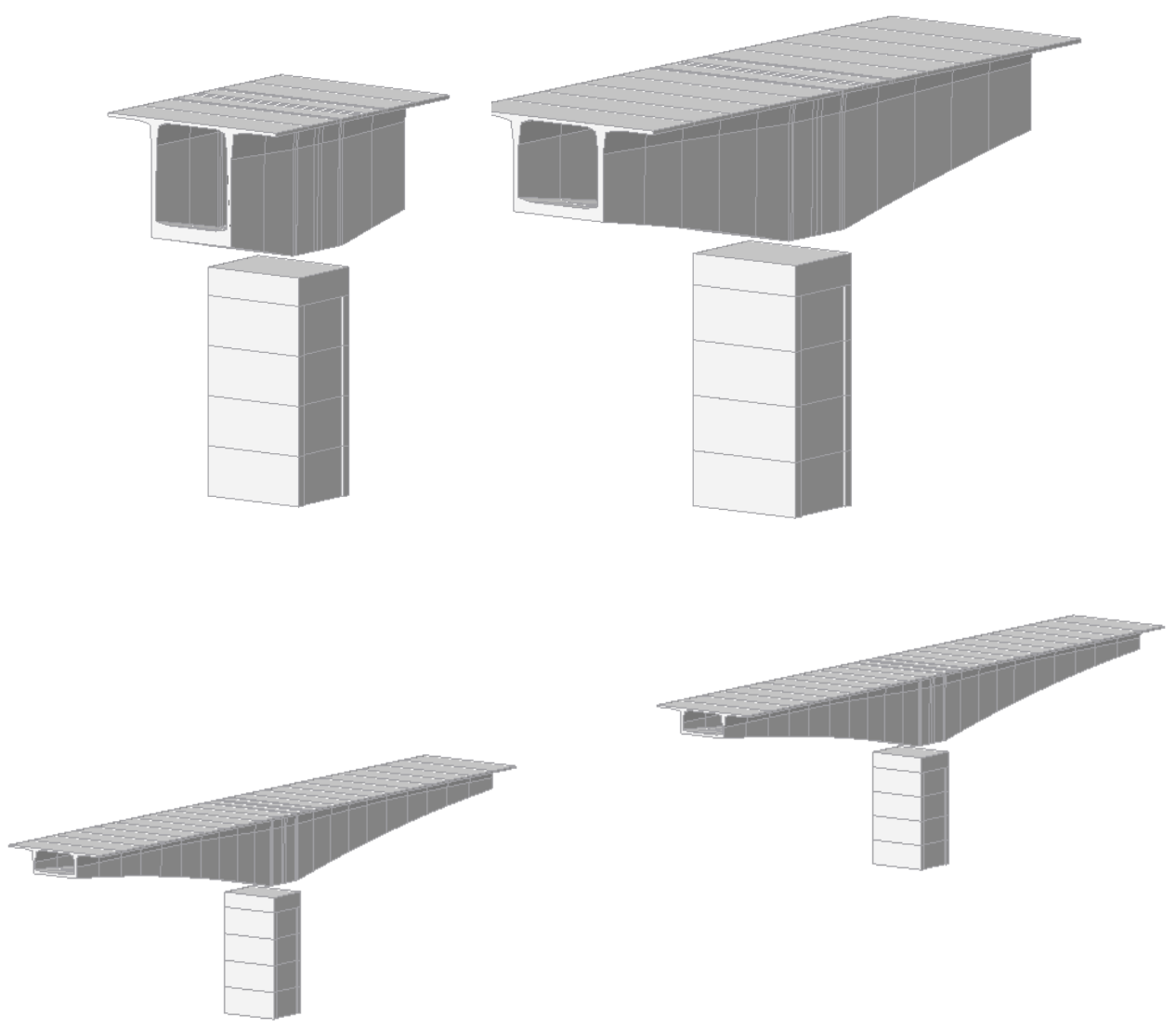

Figure 4. views of the 3D finite element model during staged construction analyses

Twenty steps averall have been taken into account, and the time-varing material properties have been introduced in the constitutive model in order to account for long term effects. The used model for evaluating time effect is of course the CEB-FIP one, represente by the following picture:

Of course, thermal effect have been taken into account both for what concerns daily and seasonal variations. 
ROMANIAN JOURNAL

OF TRANSPORT INFRASTRUCTURE

Aldo Giordano, Giorgio Pedrazzi, Giovanni Voiro,

Balanced cantilever girder bridge over the Danube - Black Sea channel

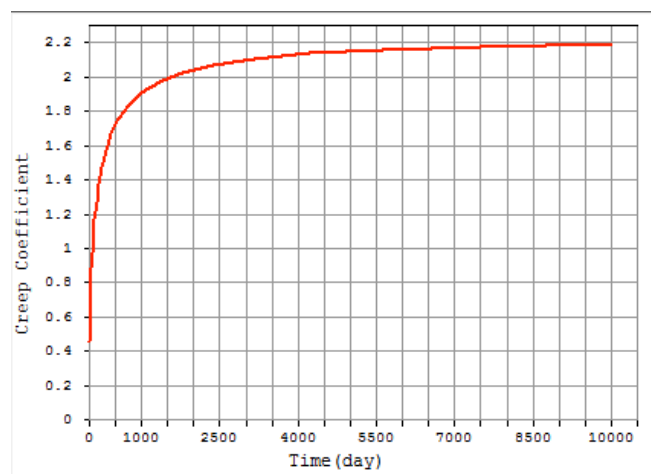

Figure 5. CEB-FIP creep model

Special attention have been paid to the modeling of the bearing devices, which are of the friction pendulum type, as shown in the following pictures.
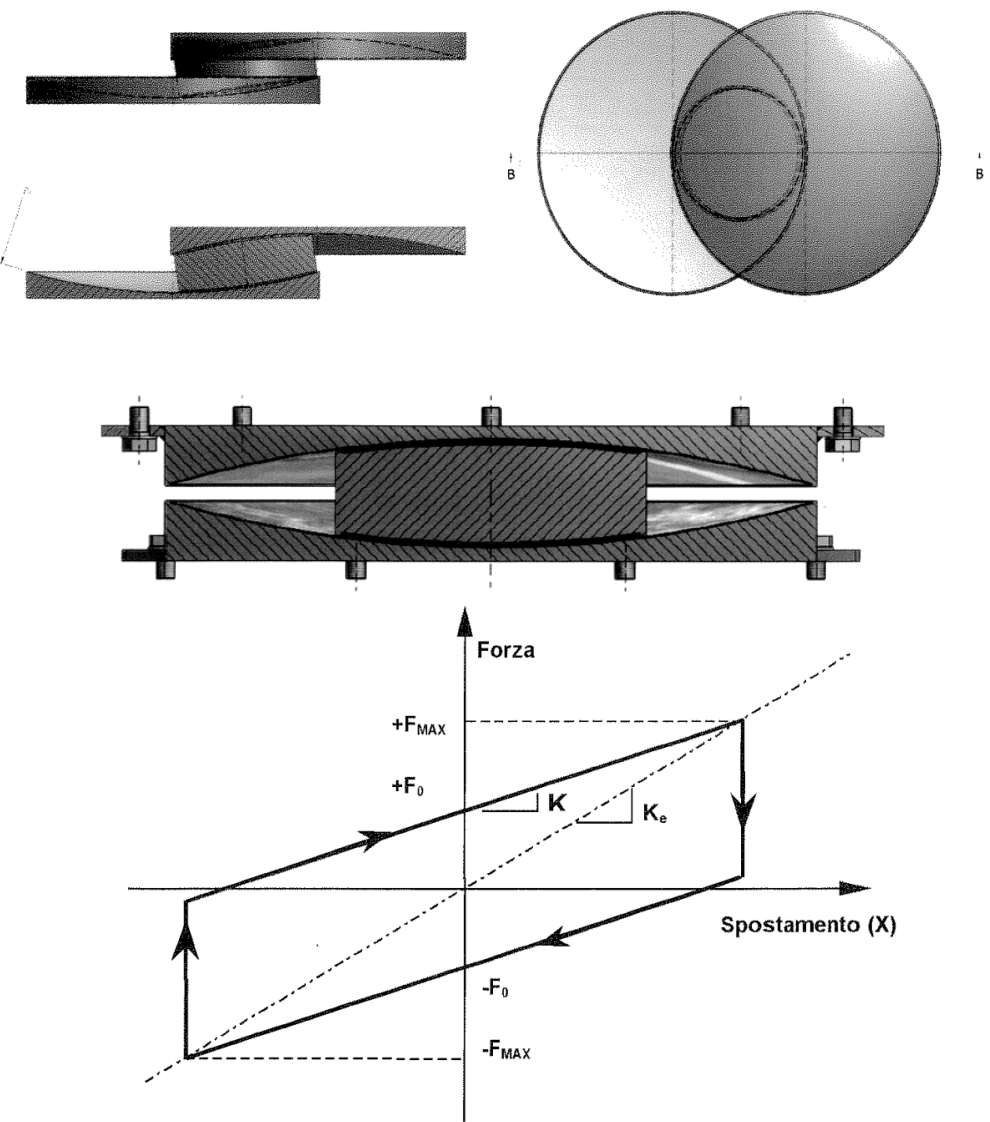

Figure 6. Friction pendulum isolator with cyclic behavior 
ROMANIAN JOURNAL

\section{OF TRANSPORT INFRASTRUCTURE}
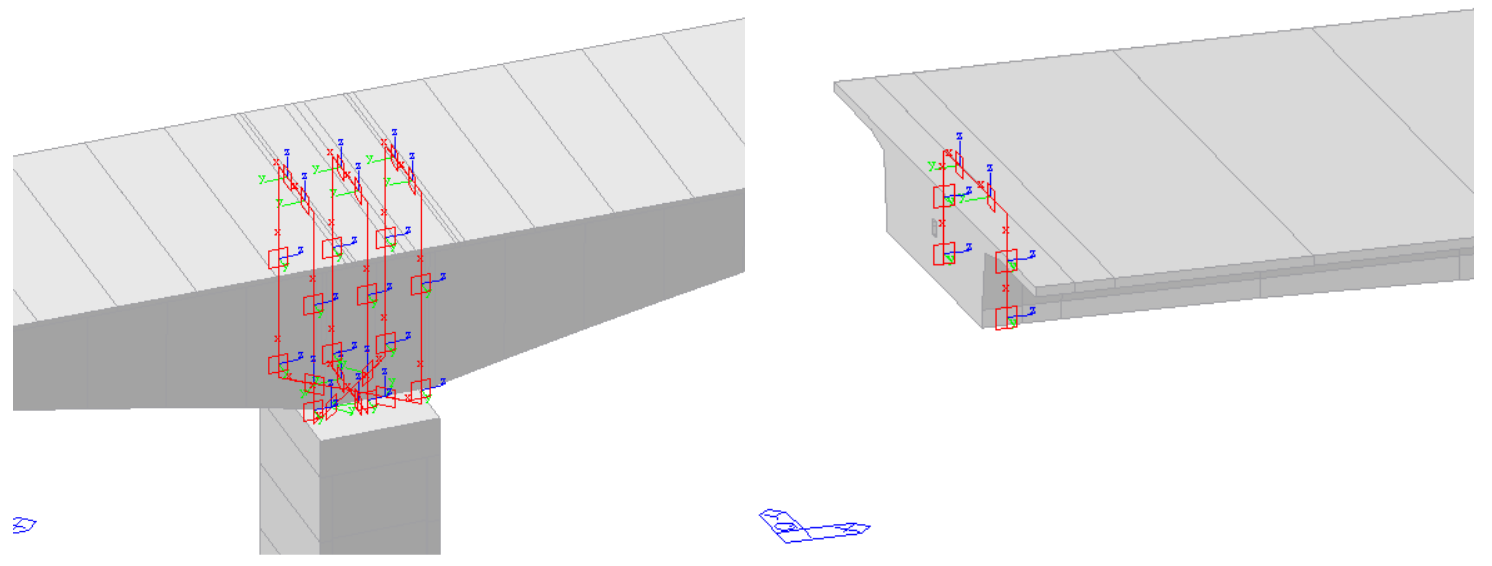

Figure 6. Friction pendulum as modeled in the software program

A very interesting possibility from the computational point of view is the possibility provided by the software of considering in each construction stage the presence and/or activation of the post-tensioning cables, which are a special characteristic of this kind of bridges, with proper constitutive model for the steel, which also takes into account time effect.
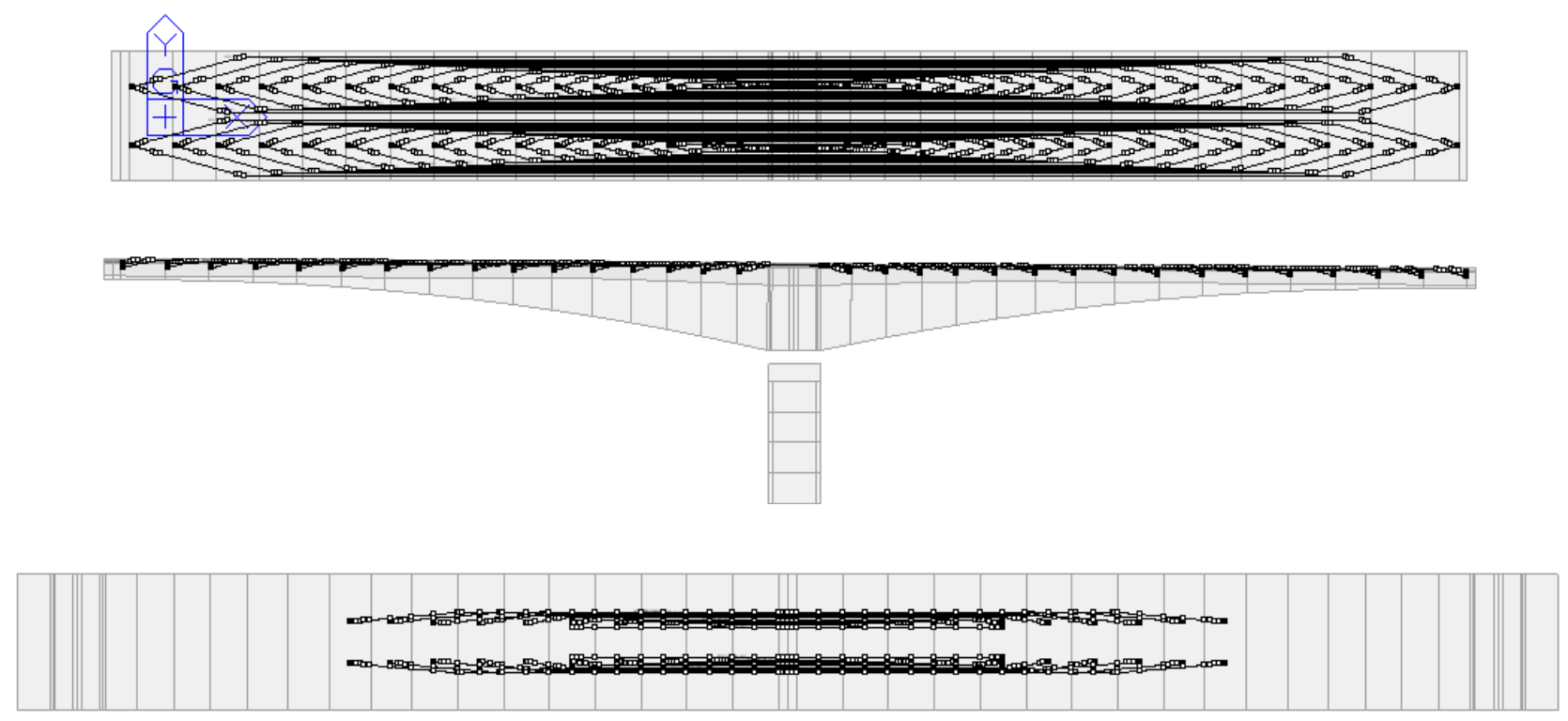

Figure 7. Post tensioning cables 
ROMANIAN JOURNAL

OF TRANSPORT INFRASTRUCTURE

Aldo Giordano, Giorgio Pedrazzi, Giovanni Voiro,

Balanced cantilever girder bridge over the Danube - Black Sea channel
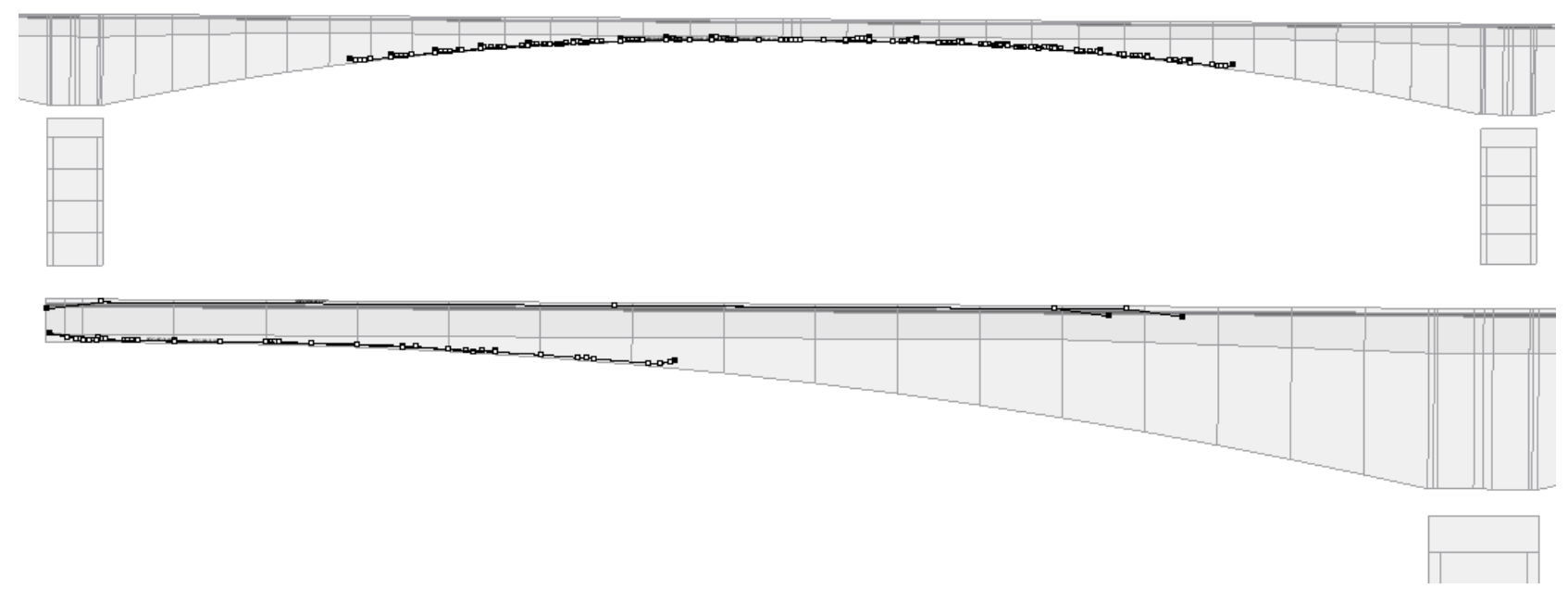

Figure 8. Post tensioning cables at intrados

Once the finite element model had been set up and analyzed under all the construction stages, the code-required conventional loads have been applied, as summarized in the following pictures, which, for paper length limits, cannot cover each and every load considered.

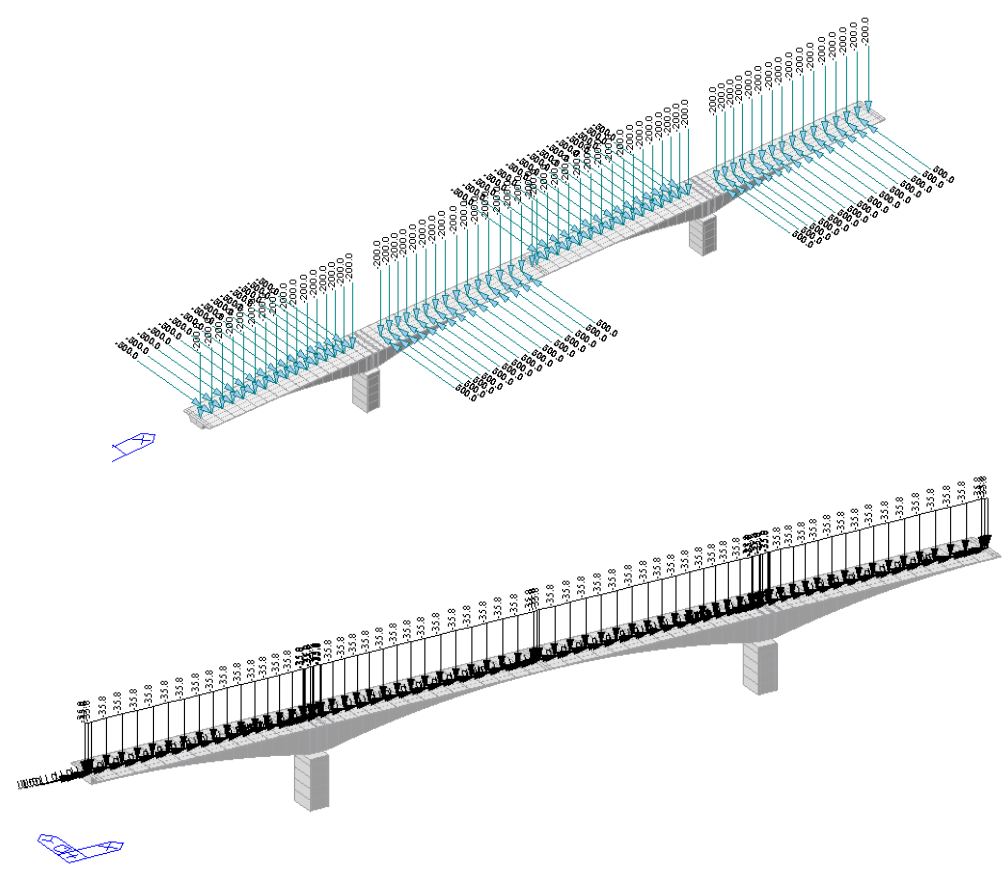

Figure 9. Some static load conditions 

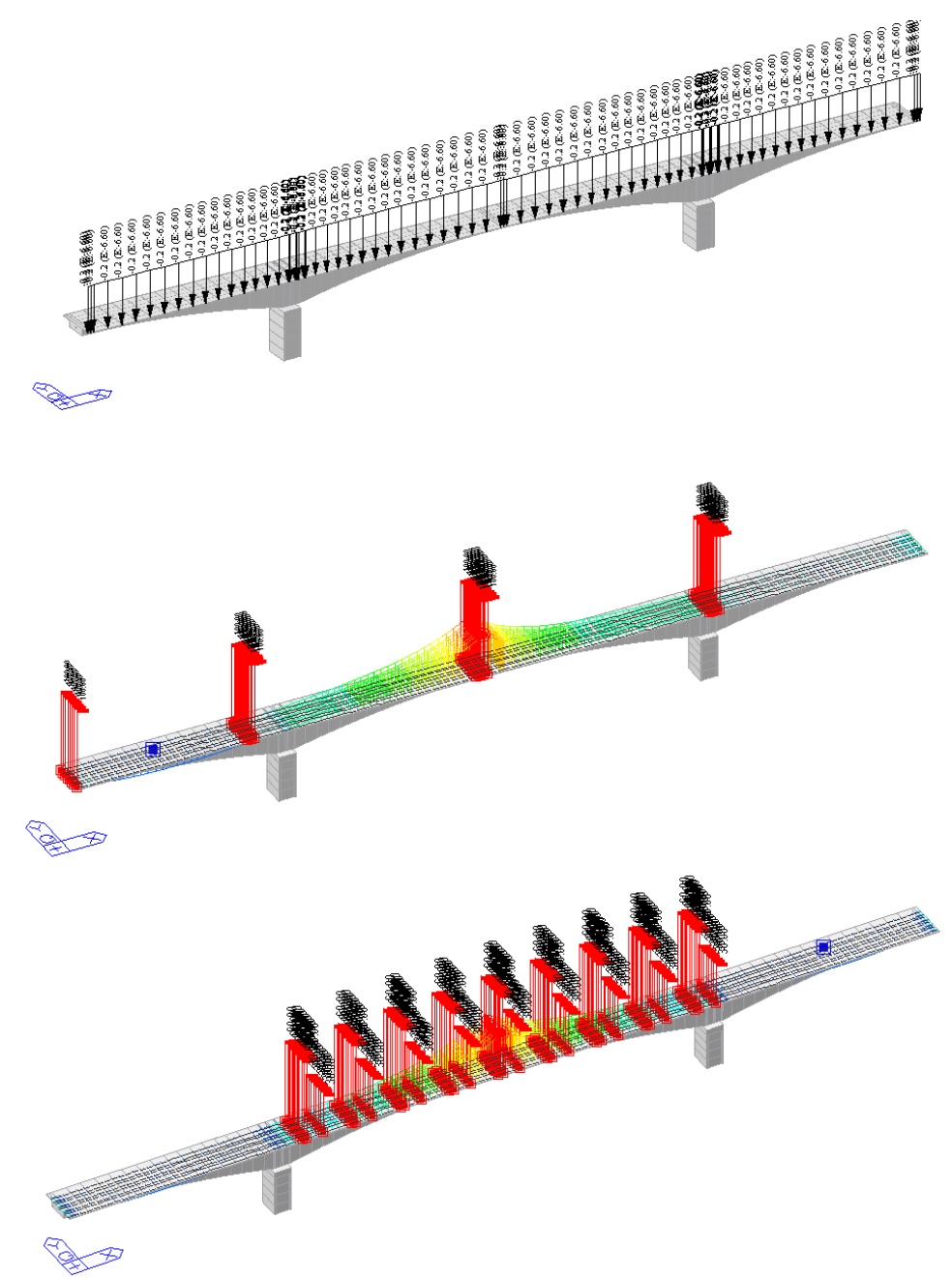

Figure 10. Additional loading conditions

For the seismic analyses, the model is characterized by the use of bridge supports of the "friction pendulum" type both at piers and abutment of the bridge. In the equivalent linear analysis, elastic constraints with the following stiffness have been taken into account.

Piers $\mathrm{K}=16.345 \mathrm{kN} / \mathrm{m}$

Abutements $\mathrm{K}=1.960 \mathrm{kN} / \mathrm{m}$

Subsequently, linear analyses using earthquake spectra provided by the Eurocodes + National annexes have been used performed. In the following figure, one of the vibration modes is depicted, and the vibration periods are indicated in the relevant table. 
ROMANIAN JOURNAL

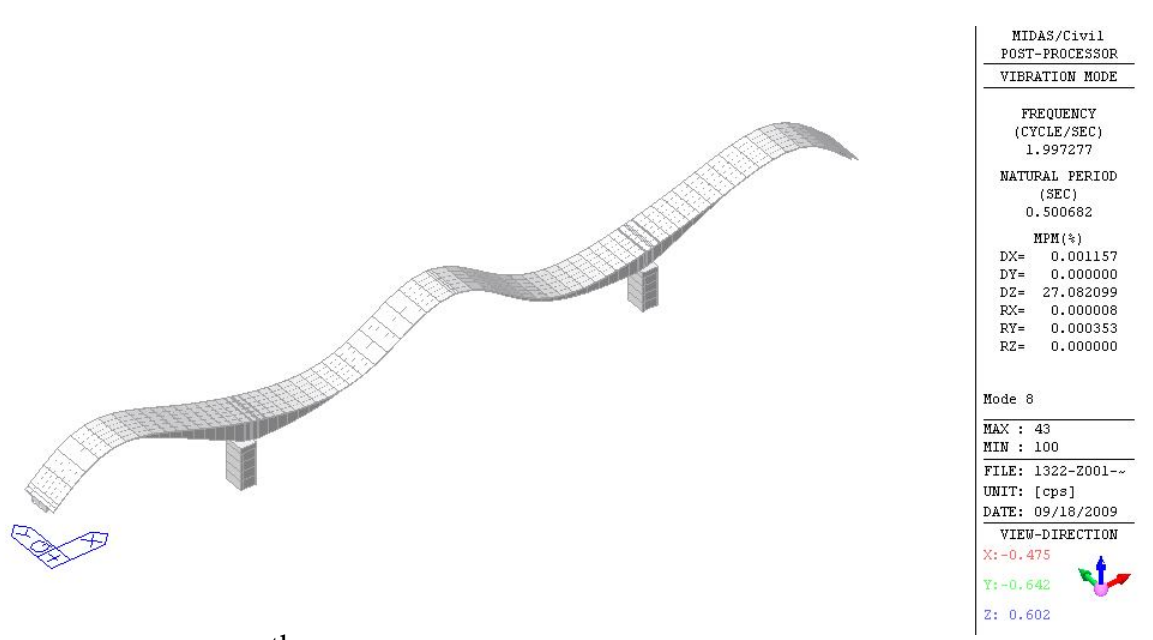

Figure 11. $8^{\text {th }}$ vibration mode (first vertical mode)

\begin{tabular}{rrrrr} 
Mod Nr. & $\begin{array}{l}\text { Fequency } \\
\text { (rad/sec) }\end{array}$ & $\begin{array}{l}\text { Frequency } \\
\text { (cycle/sec) }\end{array}$ & \multicolumn{1}{l}{$\begin{array}{l}\text { Period } \\
(\mathrm{sec})\end{array}$} & Tolerancy \\
1 & 2.581187 & 0.410809 & 2.434223 & $0.00 \mathrm{E}+00$ \\
2 & 2.68343 & 0.427081 & 2.341475 & $0.00 \mathrm{E}+00$ \\
3 & 2.693086 & 0.428618 & 2.33308 & $0.00 \mathrm{E}+00$ \\
4 & 3.451769 & 0.549366 & 1.82028 & $0.00 \mathrm{E}+00$ \\
5 & 4.049886 & 0.644559 & 1.551448 & $0.00 \mathrm{E}+00$ \\
6 & 7.689985 & 1.223899 & 0.817061 & $0.00 \mathrm{E}+00$ \\
7 & 8.134612 & 1.294664 & 0.772401 & $0.00 \mathrm{E}+00$ \\
8 & 12.54926 & 1.997277 & 0.500682 & $0.00 \mathrm{E}+00$ \\
9 & 15.06868 & 2.398254 & 0.41697 & $0.00 \mathrm{E}+00$
\end{tabular}

The global analyses have been completed with more refined ones, performed on different parts of the structure, for which local models have been set up and subjected to properly arranged loads.

For space reasons, only a few of such models have been reported in the following figures, along with some relevant results in terms of stresses and equivalent internal forces.

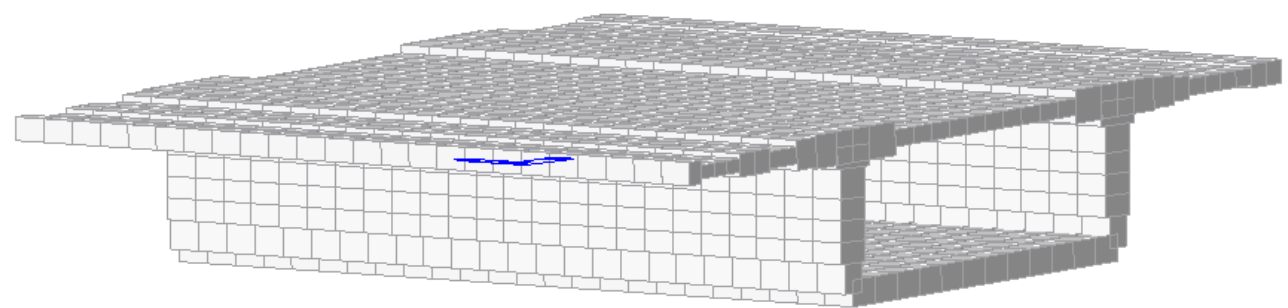

Figure 12. Partial model of a segment 


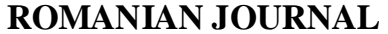 OF TRANSPORT INFRASTRUCTURE}

Aldo Giordano, Giorgio Pedrazzi, Giovanni Voiro,

Balanced cantilever girder bridge over the Danube - Black Sea channel
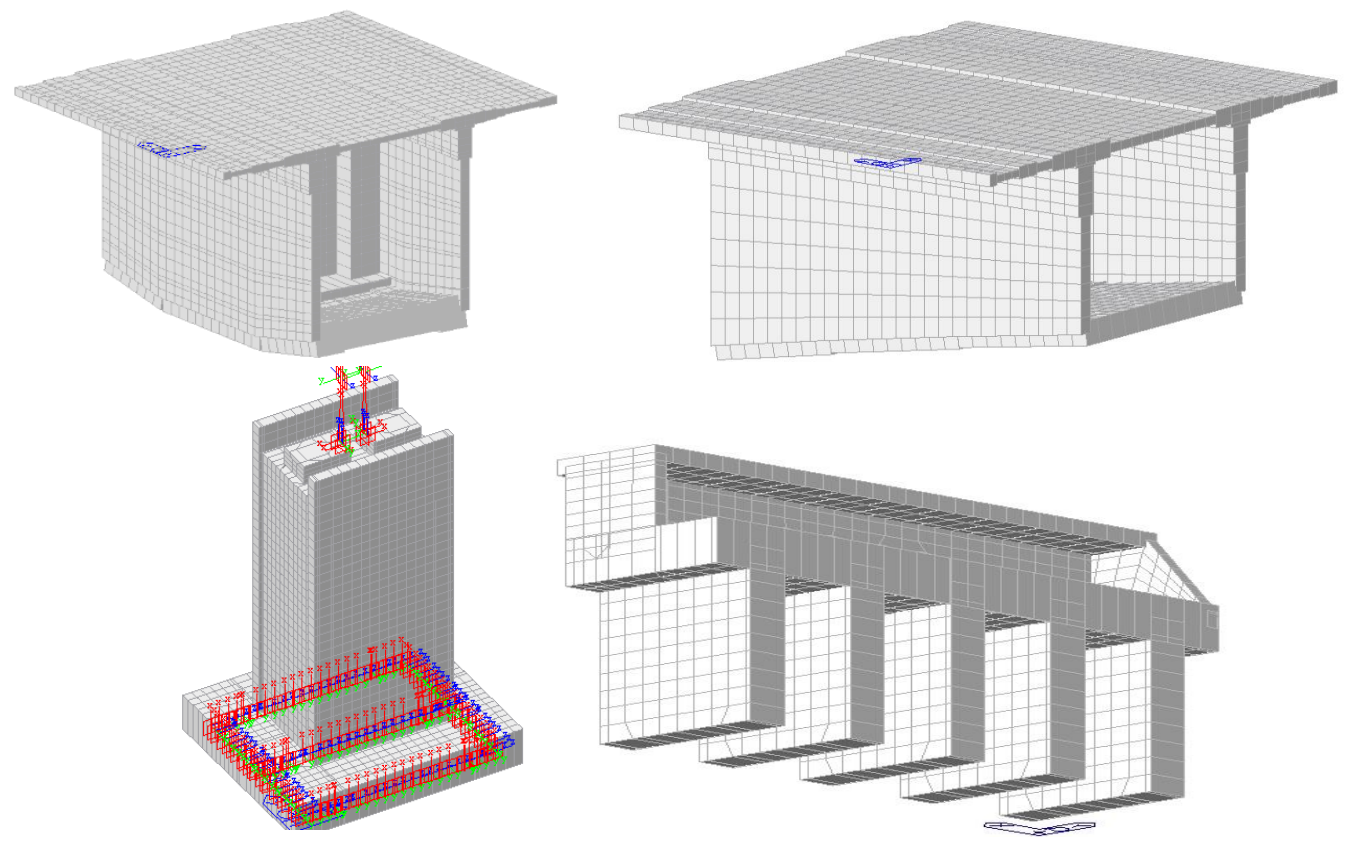

Figure 13. Additional partial models
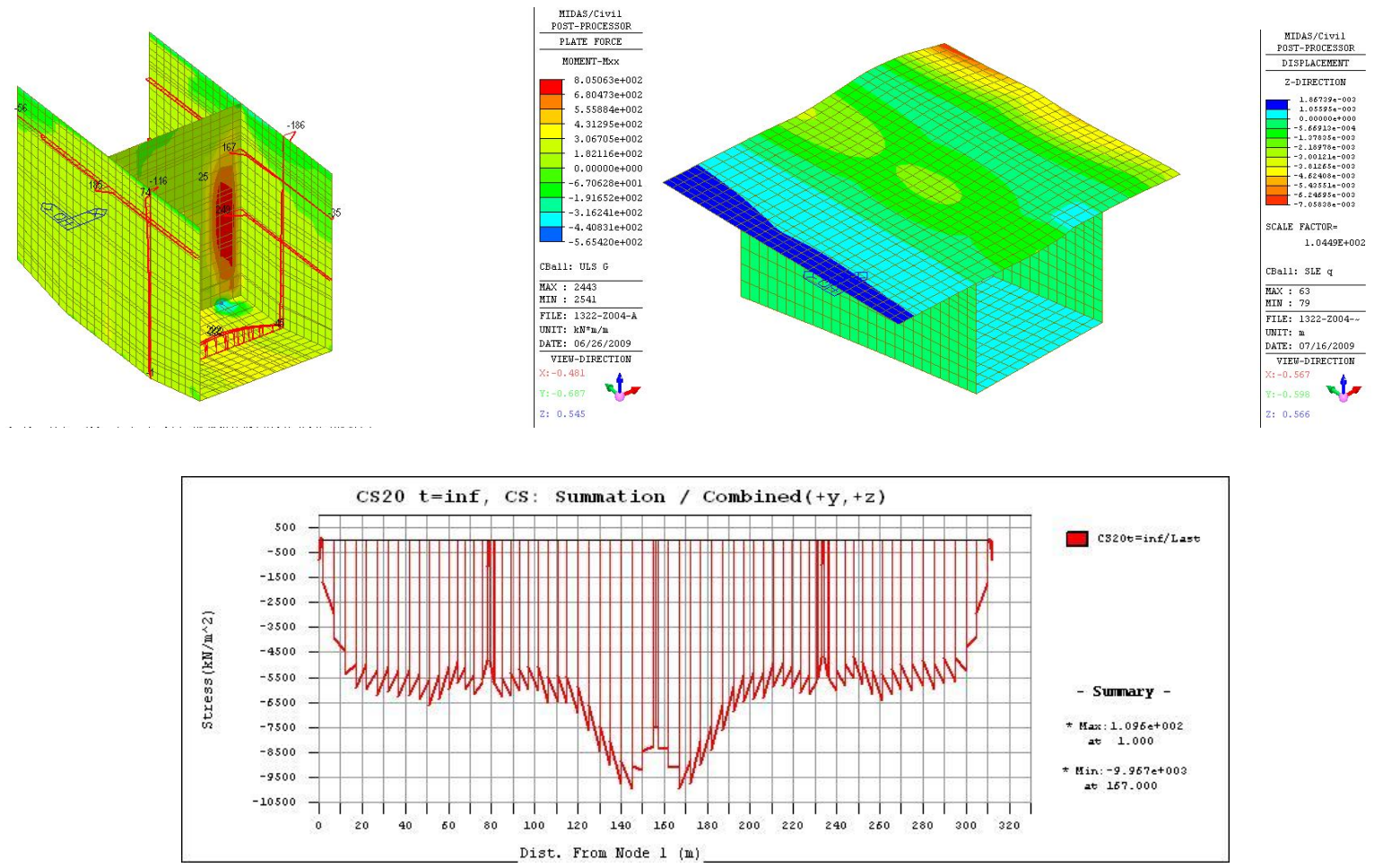

Figure 14. Some results in terms internal forces and stresses 


\section{ROMANIAN JOURNAL OF TRANSPORT INFRASTRUCTURE}

\section{ERECTION}

Once all the design aspect have been suitably treated, a very detailed method statement for construction, and subsequent testing, has been established in order to respect the analysis assumption in each phase of the erection, that for this kind of bridge play a key role.

The following figures show some of the construction phases.

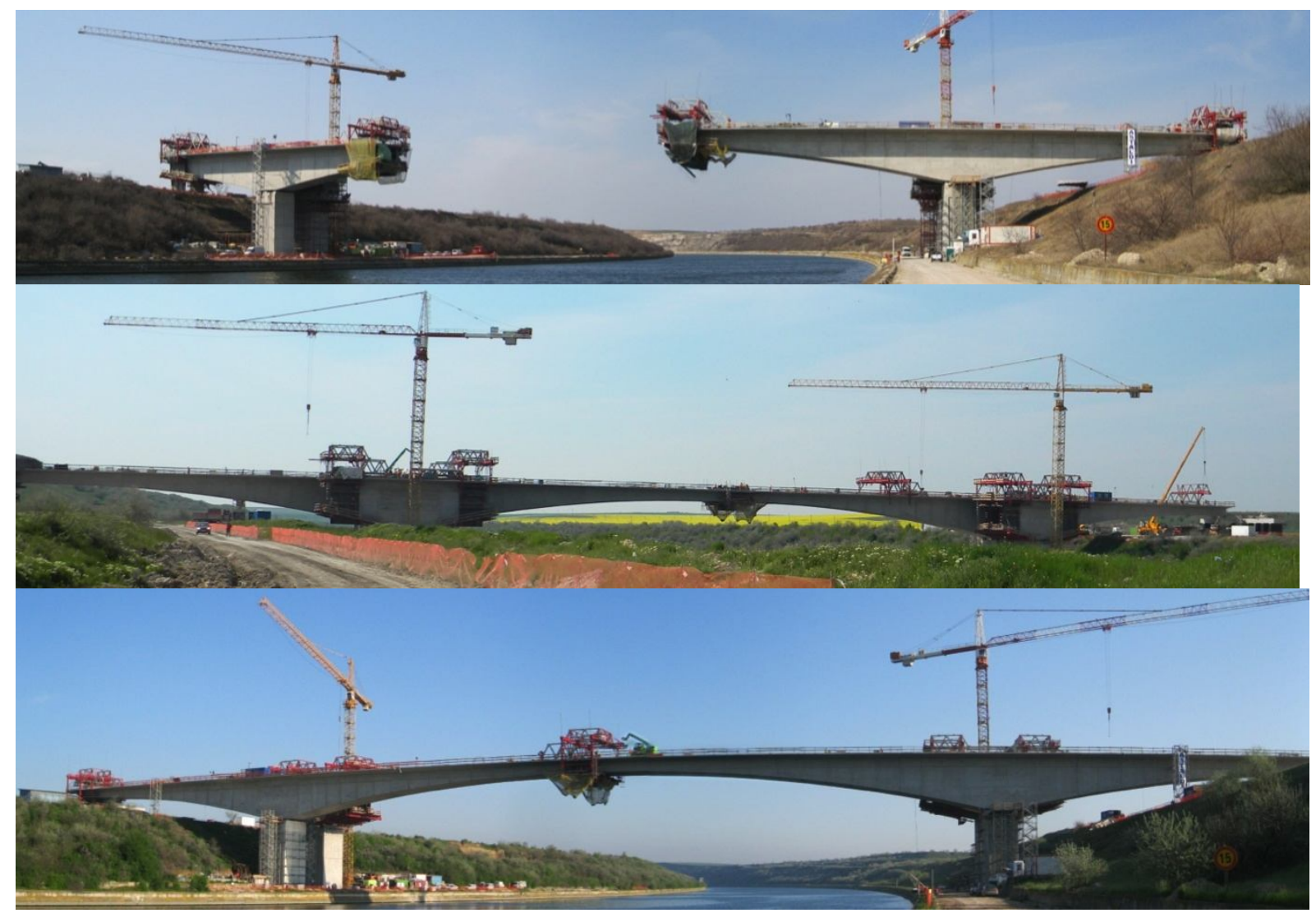

Figure 11. Come construction phases

\section{CONCLUSIONS}

This paper, within the limits of these few pages, describes the process the authors have followed in the design of a composite steel-concrete viaduct with some peculiar characteristics. The approach followed has made possible a particularly cost effective realization, while at the same time retaining very good structural performances and beautiful aesthetics. Some concepts, such as shape effects and extensive use of non-linear analysis, have helped in streamlining the process balancing the allegedly opposite needs of cost saving and structural performance. 